\title{
Intonation Focus in the Interlanguage of a Group of Spanish Learners of English ${ }^{1}$
}

\section{Francisco Gutiérrez Díez University of Murcia fgut@um.es}

\begin{abstract}
The present paper is a report on intonation errors made by a group of Spanish learners of EFL in their last year of Secondary School ( $2^{\circ}$ Bachillerato). More specifically, we attempt to identify and classify the errors relating to the students' use of intonation to highlight information. With this aim in mind, we have used the tonetic approach to intonation analysis as the theoretical framework for the study. When comparing the students' performance with English native speakers', two types of errors emerge, interference and developmental. Once more, contrasts between English and Spanish regarding the focalisation of information by means of intonation (tonicity) can serve the purpose of explaining some of the errors (interference). At the same time some developmental errors are detected in the students' intonational interlanguage.
\end{abstract}

\section{Introduction}

The present study deals with the acquisition of certain aspects of English intonation by a group of students of secondary education in their second year of Bachillerato (i.e., high school final year). Such aspects have to do with the organization of information by means of pitch-accentual prominent within the tone unit.

Within-word prominence is signalled by lexical stress. Within the speech chain, the information carried by some words is signalled as prominent against a background of nonprominent words. Inter-word prominence is signalled by rhythmic stress and by intonation. Lexical stress is a lexical feature and lexically-stressed words become the input to rhythmic 
stress, the rules of which can determine a rearrangement of lexical stress patterns in some words (ninete.en nrincess, ranteen. stc.) or its sunnression in the sn-called "ocammatical'

(or 'function') words. The output of rhythmic stress, in turn, becomes the input to intonational (or pitch) accentuation, thus yielding the final configuration of prominence distribution within the tone unit.

In our opinion, only within the prosodic hierarchy of the prominence assignment just outlined can we look for a coherent explanation of prominence, independently of the subtleties of different theoretical models so far used to account for prosodic prominence, and its integration within the overall language system. Our study is restricted to two prominent points within the tone unit: the onset and the intonational nucleus. In the next paragraph we shall refer to the theoretical framework used in this study.

\section{Theoretical framework}

We are using the 'tonetic approach', a branch of the 'prosodic approach' used in the British tradition of 'configuration analysis' of intonation as opposed to 'level analysis' or to the more recent 'mixed' types of analyses stemming from autosegmental phonology, where both pitch-generated configurations and pitch levels are highlighted. For more details about different theoretical approaches and models, see Gutiérrez (1999) and Ramírez (2003).

In our opinion, compared to more recent intonation transcription models, pitch configuration approaches, without losing plausibility as theoretical descriptions, lend themselves to a more transparent application to the learning/teaching field, in particular, to the analysis of interlanguage intonation. Accordingly, we shall use here a metalanguage pertaining to the tonetic approach to intonation.

Within the tonetic approach we first assume the total pitch contour unit, which has been variously designated as intonation group (Kingdon, 1958; Cruttenden, 1986), tone unit (Crystal, 1969; Tench, 1997), or tone group (Palmer, 1922; Jassem, 1952; Schubiger, 1958; O'Connor-Arnold, 1961; Halliday, 1967 and 1970).

In accordance with the tonetic approach, the tone unit has constituent parts which allow for paradigmatic contrasts. The existence of such constituents would explain the phonological gradation of functional contrasts (what some analysts call 'primary' and 'secondary' meanings of intonation) and an increase in the predictive power of the description by positing a small number of structural elements in the tone unit: prehead, head and nuclear tone. The prehead is made of unstressed syllables at the beginning of the tone unit. The head begins with the first pitch-accented syllable, the onset, and extends up to, but not including, the nuclear tone. The nuclear tone is the most conspicuous pitch movement over one or several words at the end of the tone unit and is made up of the nucleus plus tail (i.e. the non-accented syllables following the nucleus up to the end of the tone unit). Compound nuclear tones would have a double nucleus. The nucleus is the most important pitch-accented syllable in the tone unit.

We are interested in two of the elements that are carriers of prominence by pitch 
accentuation: the onset (Brazil et al., 1980) and the nucleus (O'Connor and Arnold, 1961; Crystal, 1969; Halliday, 1967; Cruttenden, 1986). The onset is the first pre-nuclear pitchaccented syllable in the tone unit, and the nucleus is the pitch-accented syllable of the nuclear tone, and, again, it is the most prominent pitch-accented syllable in the tone unit.

\section{Intonational focusing of information and tonicity in English and Spanish}

As indicated before, of the afore-mentioned structural elements, only two are involved in the present study: the onset, alternatively called head by others, such as Crystal (1969), and the nucleus. Regarding these two structural elements of the tone unit, we shall add a couple of observations:

1. The pitch level of the onset is an ingredient in the definition of a type of intonational contrast called key (Brazil et al., 1980), which applies both within and between tone units.

2. Meaningful contrasts due to the alternative assignment of the intonational nucleus to different words within the tone unit were grouped by Halliday (1967) under the intonation subsystem he called tonicity. This subsystem operates side by side with two other subsystems: tonality, which accounts for the contrasts due to the alternative division of one and the same lexical string into different numbers of tone units, and tone, which refers to the functional contrasts held between different nuclear tone types.

Within tonicity a distinction is made between neutral tonicity, which consists of assigning the intonational nucleus to the last 'lexical' (or 'content') word in the tone unit (example 1 below), and marked tonicity, which consists of the assignment of the nucleus to a word other than the last 'lexical' element (examples 2-4). In the examples used here we shall symbolise the nucleus by underlining the nucleus-bearing syllable. Example (1) is a sample of neutral tonicity; examples (2-4) illustrate marked tonicity.

(1) // she lives in a hotel in Glasgow //

(2) // she lives in a hotel in Glasgow //

(3) // she lives in a hotel in Glasgow //

(meaning: 'not in an apartment')

(4) // she lives in a hotel in Glasgow //

(meaning: 'he does not work there')

(meaning: 'not he', or 'not Paul', etc.)

Marked tonicity serves the purpose of highlighting words that bear new information or some kind of contrast by assigning the nucleus to their tonic syllable. Those words containing information that has been previously given in the course of the communication (hence 'old', 'given' or 'shared' information) cannot have the nucleus assigned to their tonic syllable. In cases of neutral tonicity the whole information content of the tone unit is highlighted (Cruttenden, 1986), as is the case in example (1). 
There exists a strong parallelism between Spanish and English regarding the assignment of the onset within the tone unit. The onset is realised on the first (rhythmically-) stressed syllable of the tone unit by giving it pitch prominence (the main acoustic correlate of such prominence being pitch obtrusion). Thus, there should not be any major problem for our Spanish learners of English to apply a pattern which is common in both languages during their assignment of tone unit onsets in English. Problems, though, begin when the students have to sort out which categories of English words are pitch-accentable precisely because they are also rhythmically stressable, a condition that ensues from the fact already mentioned that rhythmic stress is the input to intonational accentuation. It is in connection with the kinds of words which are rhythmically stressable -and hence intonationally accentable- that the two languages are in contrast with one another, thus posing potential trouble spots for Spanish learners.

In general, no 'grammatical words' (or 'function words', as they are also called in the language learning jargon), such as articles, possessive determiners, prepositions and conjunctions, receive a tone unit onset in either language. Auxiliary verbs and personal pronouns, though, behave differently in each of the two languages: they receive onset in Spanish but not in English, and that may pose a learning problem for our learners of English.

As regards tonicity, its functional load is much higher in English than in Spanish. In the latter, rather than using intonation to establish information focus, several syntactic devices are preferred for the same purpose, such as word order, changes in the theme-rheme structure and the use of cleft or pseudo-cleft sentences. While the rule for neutral tonicity in English is to place the intonational nucleus on the last lexical word in the tone unit, in Spanish the rule is to place it on the very last word, regardless of the nature of such word.

Although few authors refer to the label 'nucleus' in Spanish intonology (Gutiérrez, 1995; Cid-Uribe, 1989; Ortiz Lira, 1994; Canellada and Madsen, 1987; García Lecumberri, 1995), most authors implicitly refer to it when placing the corresponding pitch accent at the end of the intonation unit (Navarro Tomás, 1948; Gili Gaya, 1950; Gil Fernández and Fant (1984). For Kullova (1982) the 'centre of information' (the author's alternative label for nucleus) does not necessarily fall on the last stress of the sentence.

García Lecumberri (1995) studies the production and perception of intonationally marked focus in Spanish in various clause positions: the results show that Spanish speakers make use of marked focus in various degrees depending on the type of clause element. The subject, complement and predicate positions are significantly more likely to become marked focus bearers than verbs. Other results are that native informants' use of marked focus at the perception level is significantly lower than its use at the production level, and that the use of marked focus in verb position is significantly lower than in subject position. The frequency of use of intonationally-marked focus in Spanish is lower than in English. The same author (García Lecumberri, 2000) reports on the perception of English marked focus in both subject and verb position by intermediate Spanish learners of English in their second year at university. She compares the learners' performance with that of a group of English native speakers. The results show that the learners' perception of marked focus is 
significantly poorer than the native speakers' perception, and that perception of marked focus in verb position is significantly poorer than in subject position for both groups of informants.

A crucial issue for the comparison of both languages is whether marked focus can be equated with marked tonicity, i.e., whether narrow focus and nucleus must coincide. In English most authors agree on the alignment of marked or narrow focus with a displaced marked nucleus (marked tonicity), and on compulsory de-accenting of post-focal/postnuclear material; more specifically, no falling accent occurs after a falling marked- focus bearing nucleus within the same intonation unit. When there is a final rise, this is interpreted as follows: as the second branch of a complex fall-rise tone if it starts on an unstressed syllable, or the second branch of a compound fall + rise tone if it starts on a stressed syllable. In both cases marked tonicity would be signalled by the displacement of the accented syllable that initiates the falling branch of the complex/compound tone.

García Lecumberri, in pursuit of a common 'tertium comparationis' for the comparison of focus treatment in the two languages, extrapolates from English into Spanish the above mentioned alignment between marked focus and 'marked' nucleus in utterances where a marked focus-bearing falling accent is followed by another falling accent in post-focal material; in such cases, she assigns both accents to one and the same tone unit and interprets the second accent as an instance of 'partial de-accenting' on the grounds that it has a narrower pitch range than the first accent. We would like to object to such an interpretation:

a) By a widely accepted set of both internal and external criteria of tone unit delimitation, a sequence of two falls means that they belong to two separate tone units. This holds equally good for English (see Crystal 1969, Cruttenden 1986) and for Spanish (Gutiérrez 1995). Though some authors notice the exceptional possibility of a postnuclear second fall within the same tone unit in English (O'Connor and Arnold, 1961; Cruttenden, 1986), we think that such 'exceptions' are best subsumed and explained in terms of 'paratonality' (Fox, 1973); such is the name used to refer to the very frequent and non-exceptional hierarchical relationship held between successive tone units. In the present case, the narrow second fall belongs to a separate tone unit, which is subordinated to the first tone unit (Crystal, 1969; Trim 1969; Couper-Kuhlen, 1986).

b) If, in the case of Spanish, we interpreted the second fall as an instance of 'partial deaccenting' on the grounds of its smaller pitch range and the fact that it falls on old information, then we would have to extend such interpretation to low falls in general when they occur on old information and are preceded by more prominent accents within the same tone unit. We think that, once the nucleus is defined with a systemic/positional criterion -the last accent in the tone unit-, such criterion cannot be replaced by two other joint criteria, i.e., the semantic 'centre of information' criterion plus the phonetic criterion of 'greatest prominence' (i.e. the accent with the widest 
pitch glide) with the purpose in mind of aligning such more prominent accent (or would-be nucleus) with marked focus.

If our interpretation is correct, we could summarise the discussion by stating that marked focus can be intonationally signalled by one of three procedures: (a) pre-nuclear accents, (b) the last accent (i.e., the nucleus), and (c) a displaced nucleus together with the deaccenting of post-nuclear old information. Pattern (a) would cover instances of two successive falls in Spanish discussed above. Pattern (b) is typically used in Spanish. We should notice that this pattern entails the placement of a tone unit boundary after a narrow focus signalling accent/nucleus (see Sosa, 1999, below). Pattern (c) is normative (compulsory) in English whenever intonational signalling of narrow focus is chosen; in Spanish, however, it is neither compulsory nor frequent. Under our interpretation, the number of Spanish utterances in García's (1995) corpus in which marked focus is aligned with a marked/displaced nucleus would be reduced by half.

Sosa $(1999 ; 171-172)$ states that nucleus displacement is not possible in Spanish:

En lenguas como el francés, el portugués o el español, en que no es posible el desplazamiento del núcleo o "centro entonativo", un medio usado... es el de dividir el enunciado en más frases, lo cual le dará un énfasis añadido a la palabra anterior a la frontera, ya que en ella se situará el tonema.

According to Ortiz Lira (1994), the last accent of the tone unit constitutes the nucleus. He found displaced nuclei followed by de-accented material in only 8 to $10 \%$ of all the intonation units in his corpus of data.

Ladd (1996), in his discussion of FTA (i.e., "focus-to accent" alignment), warns against the universalist-reductionist stand of the radical FTA view (Gussenhoven, 1983), according to which the relationship between focus and accent is bi-directional, i.e., whatever is focused is accented and whatever is accented is focused. He provides numerous examples of languages that accent old information as against languages that de-accent it. He says (1996: 187) that "it would be unfortunate if models of human information processing [in different languages] turned out to be models of how to speak English".

To complicate things further, de-accenting of old information is compulsory in English, but in Spanish it is neither compulsory nor very frequent. Cruttenden (1993) finds that some languages, amongst them English, insist on de-accenting repeated material, while others, like Spanish, strongly resist it.

Another aspect of tonicity is the existence of sharp contrasts between English and Spanish regarding the alignment of nucleus with function words. Such an alignment occurs systematically in Spanish when the function word occurs in tone unit final position. However, in English, function words in tone-unit final position can be nucleus bearers only in cases of marked contrastive focus (marked tonicity). This mean that not only marked tonicity but neutral tonicity, as well, is contrastively patterned in each of the two languages. Such contrasts, as we shall see below, constitute a stumbling block for our learners. 


\section{On tonicity errors}

There has been very little research on tonicity errors by Spanish learners of English. Ramírez Verdugo (2003), reports on a longitudinal study on the learning of English intonation by Spanish students of upper-intermediate level covering their first 3 years at university. She used a large corpus of running speech made up of read-aloud materials and spontaneous conversations. She analysed intonational errors at the production level by reference to speech roles, intonation subsystems (tonality, tonicity and tone) and learner strategies (avoidance, overuse and underuse). Marked tonicity is underused in most cases. Some frequencies of use in connection with speech roles in which marked tonicity is compulsory in English are as follow: $62,2 \%$ in statements, $57,2 \%$ in who-questions, $0 \%$ in echo questions (this one seems a case of avoidance error), $51,4 \%$ in reassurance, $45 \%$ in apologies. What seems disturbing is one of the author's concluding remarks:

...non-native and native English speakers use different intonation patterns. The difference affects all the hierarchical constituents of English intonation systems, that is, tonality, tonicity and tone. ... The longitudinal study demonstrates that there has not been any progress in the production of English intonation by Spanish learners... The results prove that the acquisition of intonation does not take place automatically, even though learners have been exposed to English for about three years" (2003: 661-662).

The 3 years mentioned in the above quotation refer to the time span of the longitudinal study; we should notice that previous to that three-year period, the students had had 6 more years of English instruction at high school.

Such results, as well as the ones presented here, seem to defy García Lecumberri's (1995) suggestion that Spanish learners of English would apply positive transfer when trying to model marked tonicity in English on account of the use of such linguistic strategy in both languages. In light of our previous discussion, tonicity contrasts between the two languages are much greater than similarities. What is really to be expected -and we seem to be getting- is negative rather than positive transfer together with error fossilization. We rather think, in keeping with findings of the weak version of $\mathrm{CAH}$ (Contrastive Analysis Hypothesis) adherents, that similarity in the present case may be a source of negative rather than positive transfer, especially when such similarity is established between the systematic use of marked tonicity to signal marked information focus in English and its occasional use in Spanish.

Before stressing similarities, further research is needed on the contrasting behaviour of grammatical and lexical words in relation to both marked tonicity and neutral tonicity and the use of both types to convey marked and unmarked information focus in both languages.

As far as we know, no study has been made so far of errors relating to onset misplacement by Spanish speakers learners of English; and no study has dealt with tonicity errors by students of Bachillerato. We are interested in the performance of our students in their second year of Bachillerato regarding their assignment of the onset and the nucleus 
in English. And it is our aim to describe the errors found in connection with the realization of those two structural elements of the tone unit as features of the learners' intonational interlanguage.

Our study is undertaken against a background of a well-attested neglect of English pronunciation in secondary education in both ESO and Bachillerato. This situation, which is described in Martinez (2004) and de Jódar (2005), can be summarised as follows: The Ministry of Education issues teaching syllabi inclusive of pronunciation; some schools issue their own complementary programs where aspects of pronunciation are included in varying qualitative degrees, but most teachers simply do not put them into practice. Most textbooks devote scarce or no attention at all to many segmental aspects of the phonological component, and no attention whatsoever to prosodic subcomponents. The university entrance examination at the end of $2^{\circ}$ Bachillerato does not include the evaluation of the oral skills and the phonological component, which, paradoxically enough, the Ministry itself has set up as teaching targets in the above-mentioned syllabi.

Ours is only a small part of a wider research project dealing with the learning/ teaching of English pronunciation in the second year of Bachillerato. Such project encompass not only the segmental level but also lexical stress, rhythm and intonation. Of the three intonation subsystems, only tonicity and onset assignment are dealt with here. It must be pointed out that the wide scope of the overall research project does not permit an exhaustive description of each of the pronunciation aspects. Accordingly, we consider the partial corpus used for the present study as adequate for a first empirical approach to detecting an typifying errors relating to onset and nucleus assignment as produced by a group of students in their second year of Bachillerato. Future studies should deal with a fourth intonation subsystem called key (Brazil et al., 1980). Such studies will have to include the typology of onsets intervening in the establishment of key contrasts, for which purpose a much greater corpus than ours would have to be used.

In the present report we shall restrict ourselves to describing and explaining basic errors relating to the assignment of both the onset and the nucleus within tone units; at the same time, we shall label the errors detected as either transfer or developmental errors.

\section{Objectives}

Our main objectives are:

1. Identification and typification of errors relating to onset assignment in the interlanguage of a group of learners in their second year of Bachillerato.

2. Identification and typification of errors relating to nucleus assignment in the interlanguage of a group of learners in their second year of Bachillerato. 


\section{The study}

\subsection{Sample}

Two samples were used: one made up of 3 native speakers of Eng! ish, who were English assistants at the University of Murcia and were speakers of Standard English; another sample was made up of 15 Spaniards who were learners of English in their second year of Bachillerato (high school); these students belonged to the same class when the study began. They were randomly selected for the present study from a wider sample that was used in connection with a different piece of research on the teaching of pronunciation by de Jódar (2005). The students' canonical proficiency level at the time of the recordings, and a month before their sitting for the university entrance examination, was pre-intermediate (equivalent to B1 level of the European Council, 2001). They were recorded a few days after they were given a test on all 4 passive and active skills using Cambridge PET (see de Jódar, 2005, for further details). Their global test scores appear in table 1.

\subsection{Instrument}

A short narrative text, with some descriptive elements, extracted from the students' official textbook, was used in the study. The text appears in Appendix 1.

\subsection{Procedure}

A first corpus was obtained by recording the reading aloud of an English text by all 3 Anglophone informants. A second corpus was obtained by recording the reading aloud of the same text by the non-native informants. Previous to their reading aloud, the informants were allowed to have a silent reading so that they could check any doubts regarding the text content. The readings were carried out at normal speed in a silent room, and the recordings were digitalised for processing ${ }^{2}$. Reading rate values for both native and non-native informants are included in table 1.

\section{Results and their discussion}

The two corpora were subjected to tonetic transcription in order to determine both nucleus and onset placement within each of the tone units. The number of onset and tonicity errors of each of the non-native informants appear in table 1 . There also appear the reading rates of both native and non-native readers, which can serve as indicators of the degree of fluency (or lack of it) in the learners' interlanguage. Below we shall refer to some effects of reading rate in the chunking of the speech chain. Here we shall point out that, regarding non-native performance, a significant negative correlation was found between the variables 'test score' and 'reading rate' of the informants (Pearson's correlation coefficient: 


\begin{tabular}{|c|cccc|}
\hline $\begin{array}{c}\text { Non-native } \\
\text { informants }\end{array}$ & $\begin{array}{c}\text { Test score } \\
\text { (on a 1/100 scale) }\end{array}$ & Onset errors & Tonicity errors & $\begin{array}{c}\text { Reading rate } \\
\text { (words/second) }\end{array}$ \\
\hline D.A. & 50,67 & 7 & 2 & 1,9 \\
M.C.B & 44,42 & 3 & 3 & 1,9 \\
C.B. & 53,12 & 7 & 3 & 0,7 \\
S.B. & 53,8 & 3 & 1 & 2,3 \\
M.P & 69,98 & 8 & 1 & 1,3 \\
J.G. & 56,24 & 2 & 2 & 1,5 \\
J.G.S & 69,33 & 8 & 1 & 1,8 \\
A.H. & 52,81 & 3 & 1 & 2,1 \\
F.M.G. & 48,2 & 5 & 1 & 1,7 \\
J.M.. & 64,19 & 3 & 1 & 2,4 \\
F.M & 48,86 & 5 & 3 & 1,8 \\
D.M. & 54,13 & 5 & 2 & 1,9 \\
M.S & 75,5 & 4 & 1 & 2,5 \\
L.S. & 37,09 & 8 & 3 & 1,7 \\
A.T. & 53,24 & 3 & 1 & 1,5 \\
Mean & 55,44 & 4,9 & 1,73 & 2 \\
SD & 10,29 & 2,15 & 0,88 & 0,62 \\
Variance & 105,87 & 4,64 & 0.78 & 0,38 \\
\hline Native informants & & & & 3 \\
D.S & - & - & - & 2.9 \\
R.B. & - & - & - & 3,1 \\
W.K. & - & - & - & 3 \\
Mean & - & - & - & 0,1 \\
SD & - & - & - & 0,01 \\
Variance & - & & - & \\
\hline
\end{tabular}

Table 1. Non-native speakers' test scores, onset placement errors, tonicity errors and reading rate.

-643 ; p-value: 0,010 ). This means that the higher the test scores the fewer the tonicity errors.

\subsection{Results relating to onset placement}

The results relating to onset placement are shown in tables 1 and 2. The 3 Anglophone informants always placed the onset on the first rhythmically-stressed syllable of the tone unit. The total number of onsets is 108 . That means that, out of a total of 119 tone units, 11 tone units lack an onset syllable, a result which is in keeping with the fact that the onset syllable is an optional element of the tone unit, as agreed by all analysts (see Cruttenden, 1986; and Tench, 1996).

Though tonality is not within the scope of the present paper, we just want to point out that the number of onsets and intonational nuclei obtained is the direct result of handling the division of the chain of speech into tone units, something which has been defectively 
carried out by our learners, thus yielding the results to be commented in the next paragraphs.

\begin{tabular}{|l|c|c|c|c|c|}
\hline & $\begin{array}{c}\text { Total number } \\
\text { of tone units }\end{array}$ & $\begin{array}{c}\text { Tone units } \\
\text { without onset }\end{array}$ & $\begin{array}{c}\text { Tone units with } \\
\text { onset }\end{array}$ & $\begin{array}{c}\text { Onsets on } \\
\text { stressed } \\
\text { syllable }\end{array}$ & $\begin{array}{c}\text { Onsets on } \\
\text { unstressed } \\
\text { syllable }\end{array}$ \\
\hline $\begin{array}{l}\text { Native } \\
\text { informants }\end{array}$ & 119 & 11 & 108 & 108 & - \\
\hline $\begin{array}{l}\text { Non-native } \\
\text { informants }\end{array}$ & 925 & 466 & 459 & 475 & 74 \\
\hline
\end{tabular}

Table 2. Number of tone units and onsets in the corpora of both native and non-native speakers of English. Correctly-assigned onsets appear in the 4 th column and incorrectly-assigned onsets appear in the 5 th column.

The 15 non-native informants produced 925 tone units, which means almost 8 times the number of tone units produced by the native informants (119). Taking into account the 5-to1 proportion of non-native informants (15) as against the native ones (3), the number of tone units produced by the former should have been no larger than 5 times the number of those produced by native informants.

The explanation for the excessive number of tone units produced by the learners should perhaps be sought in their limited command not only of the segmental content of pronunciation but also of the morphosyntactic level, and, as a consequence, to their limited prosodic fluency. Another result is that, while almost all the native informants' tone units have an onset ( 108 tone units out of 119 , in fact), only half of the tone units produced by the non-native informants do have an onset (in fact, only 459 tone units out of 925). Conversely, while the 3 native speakers produced 11 tone units without an onset, the 15 learners produced 466 , i.e. over 42 times the amount produced by the native informants. The greater the number of tone units in a text, the smaller the number of stressed words per tone unit and, therefore, the smaller the overall number of onsets. Many of the learners' tone units contain only one rhythmic stress, which, by rule, must bear the nucleus, thus leaving no room for an onset. This result seems, therefore, linked to the students' lack of fluency.

Both the greater number of tone units and the smaller amount of onsets produced by non-native informants is directly linked to the latter's smaller mean reading rate than that of the native informants ( 2 and 3 words per second, respectively) (see table 1 ). Non-native speakers also made numerous pauses within and between tone units, a fact which contributes to increasing the above-mentioned effects: the slower the rate the larger the amount of tone units and nuclei, and the larger the amount of tone units, the fewer the amount of onsets. Such deviations from the native informants' output do not constitute errors per se, but are clear indicators of the learners' lack of fluency as a feature of their interlanguage.

We offer below some samples of errors relating to onset placement by non-native English speakers. We shall use the symbol ( ) to represent the onset in our corpora. The 
asterisk $\left(^{*}\right)$ symbolises incorrect onset placement.

(1) $/ /$ Now $/ / *$-with his new identity $/ /$ and -new face $/ / \ldots$

(2) // Pas cal laughed to himself $/ /{ }^{*}$ as he thought $/ /$ of his in ${ }^{-}$genious plan //

(3) // ${ }^{-} \mathrm{He}$ had taken the priceless pieces // of $\mathrm{Co}^{-}$lombian art belonging // to ${ }^{*-}$ his father $/ / \ldots$

(4) ...// and had - left the country // before-anyone noticed // they *-were gone //

(5) ...// be ${ }^{-}$longing to his father // and *-had left the country $/ / \ldots$

(6) // How *- can you accuse $/ /$ or $^{-}$even suspect a dead man $/ /$

(7) $/ /$ Now $/ /$ with ${ }^{*}$ his new identity $/ /$ and ${ }^{-}$new face $/ / \ldots$

(8) $/ /$ as $^{-}$cal the black sheep of the family $/ /$had disappeared $/ /$on a trip $/ /{ }^{*-}$ to South America $/ / . .$.

(9) ...// he had returned to the scene $/ /$ of $*^{--}$his crime to buy // the ${ }^{-}$house his father had thrown $/ / *-$ him out of $/ /$

(10) ...// of his ${ }^{-}$crime to buy // the house his father $/ / *^{*-}$ had thrown him out of $/ /$

(11) // His father $/ /{ }^{*-}$ had threatened $/ /$ to ${ }^{-}$cut him off $/ /$and leave ${ }^{*-}$ him without $/ /$ a penny $/ / \ldots$

(12) // He wondered // what his cousins // *- would say $/ / \ldots$

It can be seen that errors consist of placing the onset on prepositions (examples 1 and 2); on auxiliary and modal verbs $(4,5,6,10,11$, and 12$)$, which are not expected to bear an onset; conjunctions (1); possessive determiners ( 3,7 and 9$)$; personal pronouns, which are not stressed but for emphatic reasons, an exception not present in example (11). Besides, in almost all the alluded examples, except (1) and (2), the onset-bearing syllables are adjacent to rhythmically-stressed syllables that belong to neighbouring words; this is a violation of the 'avoidance-of-stress-clash' rule (Bolinger 1981; Monroy and Gutiérrez 1994).

\subsubsection{Discussion of results relating to onset placement}

We would like to make an observation regarding the qualitative aspect of errors in onset assignment: in order to shed light on such errors, we need to recall an old distinction between grammatical (or function) words and lexical (or content) words. The first consequence of assigning the onset to grammatical words is an associated error consisting of the use of the strong phonological forms of such words, thus distorting their phonological makeup, since the use of strong forms is linked, especially in monosyllabic words, to rhythmic stress and, potentially also, to intonational accent in general and to unit onset in particular. Monosyllabic grammatical words are usually unstressed and, therefore, pronounced with weak forms, i.e., with the vowels [?] or [é]. The result of onset misplacement is that the distribution of prominence over the tone unit is odd to native ears, since unexpected prominence is produced in the wrong places, or prominence is lacking in places where it is a must, and, as a result, communication is hindered. 
Another observation has to do with the relationship between rhythmic stressing and accentuation by intonation, in our case, of the onset-bearing syllable. Examples (1-12) illustrate a feature common to all errors found in the corpus: every onset misplacement is accompanied in the same onset-bearing syllable by a wrongly assigned rhythmic stress. In section 3 above we said that rhythmic stressing is prior to intonational accentuation, since the latter applies on the output of the former, which entails that only rhythmically-stressed syllables can receive an onset. As it is, this means that every error of onset placement ontogenetically implies an error of rhythmic stressing, which is what exactly happens in the English of our learners.

It is commonly held that linguistic stress correlates are, in varying trading relationships, intensity, duration and pitch of the stress-bearing syllable; in the case of intonational accentuation, pitch obtrusion acts as the main correlate of prominence and this applies to both the onset and the nucleus syllables. A corollary of the previous is that correct assignment of onset and nucleus implies a previous mastery of rhythmic stressing.

It is a known fact that in both English and Spanish prepositions, conjunctions and possessive determiners do not carry either rhythmic stress or intonational onset but for emphatic reasons. Given such a coincidence between the two languages, we can characterise our learners' errors regarding onset placement on these three types of words as developmental errors. Turning to the question of emphasis, the text used in our study (see Appendix 1) is a narrative text, with some descriptive elements included, and no context has been detected that might allow an emphatic reading aloud with a subsequent emphatic accentuation.

On the other hand, the treatment of auxiliary verbs and personal pronouns is different in Spanish than in English: in the former language both types of words carry rhythmic stress and a full vowel (i.e. non-central or peripheral, or stressed); they are also susceptible of carrying an intonational onset, especially when they are the first stressed syllable in the tone unit. In English, on the contrary, both types of words do not carry rhythmic stress, are realised with weak forms and are not susceptible of carrying an onset. Therefore, we could categorise as interference errors those made by the learners when producing such words with rhythmic stress, a strong form and an intonational onset.

\subsection{Results relating to tonicity}

\subsubsection{Errors related to neutral and marked tonicity}

As we said before, while the rule for neutral tonicity in English is to place the intonational nucleus on the last lexical word in the tone unit, in Spanish the rule is to place it on the very last word, whether it is a lexical or a function word. No cases of marked tonicity were found in the corpus by native English speakers in keeping with the nature of our text, in which no contextual clues are found that might trigger marked tonicity.

Errors of neutral tonicity consist of the assignment of the nucleus to a word different from the last lexical word in the tone unit in cases in which such assignment is banned by 
the corresponding (default) tonicity rule. Non-default rules contemplate the placement of nucleus on a word different from the last lexical one in the following cases: change of information focus, signalling 'new' versus 'given' information, contrastive focus and emphasising a word which, under non-emphatic conditions, could not bear a nucleus (Halliday, 1967 and 1970; Crystal, 1969).

Out of 925 tone units in the learners' corpus, grouped in 150 tone unit sequences (with an average of 10 sequences per learner), 26 tonicity errors were detected (see table 3 ), most of them consisting in the placement of the nucleus on a preposition occurring in tone unit final position ( 23 errors). There is one instance of nucleus placement in a possessive determiner which surely implies a previous tonality error, since no determiner can be intonationally separated from its phrase-head (Gutiérrez, 1983); and 2 instances of nucleus placement on a personal pronoun. All errors have to do with a wrong realization of neutral tonicity. No errors have been detected regarding marked tonicity for two likely combined reasons: a) the lack of contextual clues in the text that might trigger canonical marked tonicity and the reluctance to using such type of tonicity in Spanish at the production level.

\begin{tabular}{|l|l|l|l|l|}
\hline Focused element & Preposition & Personal pronoun & $\begin{array}{l}\text { Possessive } \\
\text { determiner }\end{array}$ & $\begin{array}{l}\text { 'Given' } \\
\text { information }\end{array}$ \\
\hline Neutral tonicity & 23 & 2 & 1 & \\
\hline Marked tonicity & & & & 0 \\
\hline
\end{tabular}

Table 3. Tonicity errors made by non-native informants.

We offer below some examples of tonicity errors found in the learners' corpus:

(1) "...// had closed // it up * after // his untimely death //"

(2) "...// the family had closed // it up after* his // untimely death //"

(3) "...// and had left the country *before // anyone noticed // they were gone //"

(4) "...// he intended // to start a new life // in the house // he had grown up in //"

(5) "...// and leave* him // without a penny // ..."

(6) "//He wondered what his cousins // would say if *they // ever found out // because Pascal was dead //..."

\subsubsection{Discussion of results pertaining to tonicity}

The number of errors is rather low (26 errors out of 925 tone units). It is surprising, though, that in the absence of contexts that might favour marked tonicity the learners have wrongly produced 26 errors related to neutral tonicity. We ought to recall at this point that, according to neutral tonicity in English, only the last lexical item in the tone unit can bear the nucleus. This excludes the possibility that function words receive the nucleus when they are final in tone unit. The rule in Spanish is that the nucleus falls on the last word of the tone unit, whether it is a lexical or a function word, with the exception of enclitic personal pronouns (-le, -las, -nos, -os, etc.). 
A corollary of the above is that the two cases of nucleus-bearing pronouns in the learners' corpus are cases of interference errors. The students would have to learn not to accent English personal pronouns regardless of their subjective or objective form and of their position within the tone unit. In Spanish two rules are at work (stressing of nonenclitic pronouns versus unstressing of enclitic ones); this would explain cases of interference during the process of nucleus assignment in our learners' English.

As for the one possessive determiner and the 23 prepositions bearing a nucleus, they are tonicity errors stemming from a previous violation of the rules of the intonational subsystem called tonality, that is, the division of the chain of speech into tone units. Neither in English nor in Spanish can possessive determiners and prepositions be separated from their prepositional complements by a tone-unit boundary (as in examples (2) and (3) above). In English there is one exception regarding postponed prepositions, which must occur at the end of the tone unit, as in (7). The 24 errors pointed out above are byproducts of wrongly performed tonality, which do not follow either the English or the Spanish tonality rules, and therefore can be considered as developmental errors. The added problem is that, since the division of speech into tone units constitutes the input for the tonicity subsystem, that is, for the assignment of nuclei, the 24 tonality errors are turned into as many tonicity errors, since function words which are final in tone unit cannot be nucleus bearers in English. Again, since in Spanish the rule is to place the nucleus in the very last word of the tone unit, the 24 errors already mentioned would have to be labelled, from the tonicity perspective, as interference errors.

\section{(7) // the man whom I talked to //}

In view of the results obtained in our study and in Ramirez Verdugo's (2003) regarding the tonicity errors made by the informants covered in both studies, it is likely that they are fossilised for the simple reason that tonicity as a teaching target has been largely neglected from the very beginning of the English curriculum of such informants.

\section{Conclusions}

a) Regarding onset placement

1. Most wrong onsets detected in the corpus are placed on canonically unstressed syllables of modal and auxiliary verbs, possessive determiners and personal pronouns.

2. Since prepositions, conjunctions and possessive determiners behave similarly in both English and Spanish regarding rhythmic stress and intonational onset, i.e. they do not carry either form of prominence, errors consisting in stressing or accenting such words in onset position would constitute developmental errors.

3. Auxiliary and modal verbs and personal pronouns behave differently in the two languages, since they carry rhythmic stress and are susceptible of taking an onset in Spanish 
but not in English. With such a contrastive perspective errors consisting of the placement of either rhythmic stress or intonational onset on such words in English would be categorised as interference errors.

b) Regarding nucleus placement

1. Most of the errors detected are related to neutral tonicity, among them, some interference errors consisting in assigning the nucleus to personal pronouns in tone unit final position.

2. An unexpected result is that most of the errors detected were also tonality errors having to do with the wrong intonational delimitation of prepositions from their complements. This means that tonality errors may constitute an input to tonicity errors. More specifically, developmental tonality errors can simultaneously constitute interference tonicity errors.

3. Most onset, tonicity and tonality errors found in our study are related to ontogenically previous rhythmic errors, such as stressing function words in positions and under conditions in which English would not allow rhythmic stress.

4. Though the scope of the present work did not include a study of tonality errors, it has been shown that some tonicity errors can only be fully accounted for by reference to the tonality performance of the learners'. This in turn supports the wildly-held theoretical view according to which the three intonational subsystems of tonicity, tonality and tone are tightly interrelated.

According to Major's (1987) 'Ontogeny Model' hypothesis, phonological interference errors are 'massive' at the elementary learning stage. If we consider our students to be false beginners on the grounds of their performance regarding onset placement and the related matter of rhythmic stressing, that hypothesis finds support in our data.

As indicated above, the deficiencies in the pronunciation of our students are the result of a long-term neglect of that linguistic component throughout previous years of instruction. In the meantime, the main pedagogical implication of the present study is that urgent institutional and pedagogical remedies should be implemented regarding the teaching of English pronunciation throughout secondary schooling with a special focusing on English prosody. The Ministry should include oral skills and pronunciation as test targets in the university entrance exams; otherwise both teachers and learners will continue to neglect the teaching/learning of pronunciation. If rhythm and intonation are not taught from the very beginning of the English curriculum, the result is that the students will fall short of attaining the standard proficiency levels officially allocated to each of the academic years along which such curriculum has to be implemented.

As for teaching students to avoid onset misplacement, we would like to suggest that the best strategy is to teach them to correctly place rhythmic stress. To the extent that they learn not to stress English grammatical words, onset placement will cease to be a learning problem and so would be instances of neutral tonality where grammatical words appear in 
tone-unit final position. Marked tonicity, though, would have to be specifically and explicitly taught if students are to avoid or overcome the interference stemming from the contrastive nature of tonicity in English and Spanish. If the learning of onset placement is a matter of learning not to stress grammatical words, the type of onset to be used (high, low, mid, etc.) -a matter not included in the present study-- would also have to be explicitly taught in connection with the intonational subsystem called key.

We have used a corpus whose representative power was limited to the elicitation of neutral tonicity. In order to gain a more comprehensive view of tonicity errors, further research must be done using corpora that include texts appropriate for eliciting a fairly wide representative range of marked tonicity.

It would be necessary to use a much wider variety of texts, including unscripted conversational texts; the latter typically lend themselves to the illustration of shared versus new information and their alignment with pitch accents, which is an area where the contrasts between Spanish and English are sharpest (Gutiérrez 1995). Such texts could elicit a wider picture of our learners' performance regarding both neutral and marked tonicity and of information focalization in their interlanguage. The study of tonicity errors at the various learning levels of secondary education would facilitate further quantitative studies from both cross-sectional and longitudinal perspectives in order to gain a wider and richer picture of the combination of three variables: types of errors, learning rates and distribution along different proficiency levels.

\section{Notes}

1. This research has been financed by Fundación Séneca (Project PI36/00797/FS/01). I would like to thank Dalilah Hebibovic for her collaboration in the recording and computation of the data used for this study.

2. Such processing includes an acoustic study of some aspects of the acquisition of intonation and rhythm not included within the scope of the present paper.

\section{Work Cited}

Bolinger, Dwight. (1981): Two kinds of vowels, two kinds of rhythm. Bloomington: Indiana University Linguistics Club.

Brazil, David, Malcom Coulthard and Catherine Johns (1980): Discourse intonation and language teaching. London: Longman.

Canellada, María Josefa and John K. Madsen, (1987): Pronunciación del español. Madrid: Castalia.

Cid-Uribe, Myriam Elizabeth (1989): Contrastive analysis of English and Spanish intonation using a computer A corpora. Unpublished $\mathrm{PhD}$ Thesis. Leeds: University of Leeds.

Couper-Kuhlen, Elisabeth (1986): An introduction to English prosody. London: Edward Arnold. Cruttenden, Alan (1986): Intonation. Cambridge: Cambridge University Press.

. (1993): "The de-accenting and re-accenting of repeated lexical items". Working Papers, Department of Linguistics and Phonetics, Lund [Proceedings of the ESKA Workshop on 
Prosody, Lund], vol. 41: 16-19.

Crystal, David (1969): Prosodic systems and intonation in English. London: Cambridge University Press.

European Council (2001): Common European framework of reference for languages: learning, teaching, assessment. Strasbourg: European Council.

Fant, Lars (1984): Estructura informativa del español: estudio sintáctico y entonativo. Uppsala: Uppsala Universitet.

Fox, Anthony (1973): “Tone sequences in English". Archivum Linguisticum 4: 17-25.

García Lecumberri, M. Luisa (1995): Intonational signalling of information structure in English and Spanish. Bilbao: Servicio de Publicaciones de la Universidad del País Vasco

. (2000): "Identificación del foco entonativo inglés por estudiantes frente a hablantes nativos". Estudios de Lingüistica Aplicada 32: 19-28.

Gil Fernández, J (1988): Los sonidos del lenguaje. Madrid: Síntesis.

Gili Gaya, Samuel (1950): Elementos de fonética General. Madrid: Gredos.

Gussenhoven, Carlos (1983): "Focus, mode and the nucleus". Journal of Linguistics 19: 377-417. Gutiérrez, Francisco (1983): "Aspectos lingüísticos de la segmentación del tono en inglés, castellano y catalán". Actas del ler Congreso de Lingüistica Aplicada. Madrid: SGEL, 179-191.

. (1995): La función demarcativa de la entonación en inglés castellano y catalán. Servicio de Publicaciones de la Universidad de Murcia.

. (1999): Modelos entonativos del inglés. Sistemas de notación entonativa. Granada: Grupo Editorial Universitario.

Halliday, Michael (1967): Intonation and grammar in British English. The Hague: Mouton. . (1970): A course in spoken English: Intonation. Oxford: Oxford University Press.

Jassem, Wiktor (1952): Intonation of conversational English. Travaux de la Société des Sciences et des Lettres.

Jódar de, Oscar (2005): Estudio sobre los efectos de un tratamiento alternativo del componente fonológico en el currículo de lengua inglesa para $2^{\circ}$ de Bachillerato. Unpublished $\mathrm{PhD}$ thesis. University of Murcia.

Kingdon, Roger (1958): Groundwork of English intonation. London: Longman.

Kullova, J. (1982): "Acerca del contorno melódico de la oración hispánica". Iberoamerica Praguensia 16: 69-76.

Ladd, D. Robert (1996): Intonational phonology. Cambridge: Cambridge University Press.

Martínez, Francisco (2004); Estudio de una intervención pedagógica para la enseñanza de la pronunciación inglesa en $4^{\circ}$ de la E.S.O. Unpublished $\mathrm{PhD}$ thesis. University of Murcia.

Major, Roy (1987). "The natural phonology of second language acquisition". In A. James and J. Leather, eds., Sound patterns in second language acquisition. Dordrecht: Foris, 207-224.

Monroy, Rafael and Francisco Gutiérrez (1994): La pronunciación inglesa simplificada: el ritmo inglés. Madrid: SGEL.

Navarro Tomás, Tomás (1948): Manual de entonación española. Madrid: Guadarrama.

O'Connor, Joseph and G. Arnold (1961, $2^{\text {nd }}$ ed. 1973). Intonation of colloquial English. London: Longman.

Ortiz Lira, Hector (1994): Contrastive analysis of English and Spanish sentence accentuation. Unpublished $\mathrm{PhD}$ thesis. University of Manchester. Manchester.

Palmer, Harold (1922): English Intonation (with systematic exercises). Cambridge: Heffer. 
Ramírez, M. Dolores (2003): A contrastive analysis of non-native interlanguage English intonation systems and their implication in the organization of information from a functional perspective. A study based on a computerized corpus of Spanish learners of English. PhD dissertation. Universidad Autónoma de Madrid.

Schubiger, María (1958): English intonation. Its form and function. Tübingen: Niemeyer.

Sosa, Juan Manuel (1999): La entonación del español. Madrid: Cátedra.

Tench, Paul (1996): The intonation systems of English. London: Cassell.

Trim, John (1969): "Major and minor tone groups in English". Le Maitre Phonetique 112: 26-29.

\section{APPENDIX 1}

"Return from the grave"

Alan Pascal knew the house would be empty because the family had closed it up after his 'untimely death'. Pascal, the black sheep of the family, had disappeared on a trip to South America, somewhere in the mountains of Ecuador. Pascal laughed to himself as he thought of his ingenious plan. He had taken the priceless pieces of Colombian art belonging to his father and had left the country before anyone noticed they were gone. Then he had arranged his own disappearance in the jungles of Colombia. How can you accuse or even suspect, a dead man? Now, with his new identity and new face, after some rather expensive plastic surgery, he had returned to the scene of his crime to buy the house his father had thrown him out of. A millionaire now, thanks to the private sale of the art, he intended to start a new life in the house he had grown up in. His father had threatened to cut him off and leave him without a penny, so he had taken the art collection and mysteriously vanished. He wondered what his cousins would say if they ever found out, because Pascal was dead and 'Mr. Roberts' was the interested buyer of the property. (Text taken from Denton, J., Lewis, R. y Siles, A. (1996). Themes for $2^{\circ}$ Bachillerato. Students book. Limassol, Chipre: Burlington, p. 33). 